\title{
CFP, the Putative Cercosporin Transporter of Cercospora kikuchii, Is Required for Wild Type Cercosporin Production, Resistance, and Virulence on Soybean
}

\author{
Terrence M. Callahan, ${ }^{2}$ Mark S. Rose,,${ }^{1,2}$ Maura J. Meade, ${ }^{2}$ Marilyn Ehrenshaft, ${ }^{2}$ and \\ Robert G. Upchurch ${ }^{1,2}$ \\ ${ }^{1}$ Agricultural Research Service, U.S. Department of Agriculture, and ${ }^{2}$ Department of Plant Pathology, North \\ Carolina State University, Raleigh 27695-7616 U.S.A. \\ Accepted 9 June 1999.
}

\begin{abstract}
Many species of the fungal genus Cercospora, including the soybean pathogen $C$. kikuchii, produce the phytotoxic polyketide cercosporin. Cercosporin production is induced by light. Previously, we identified several cDNA clones of mRNA transcripts that exhibited light-enhanced accumulation in $C$. kikuchii. Targeted disruption of the genomic copy of one of these, now designated $C F P$ (cercosporin facilitator protein), results in a drastic reduction in cercosporin production, greatly reduced virulence of the fungus to soybean, and increased sensitivity to exogenous cercosporin. Sequence analysis of $C F P$ reveals an 1,821-bp open reading frame encoding a $65.4-\mathrm{kDa}$ protein similar to several members of the major facilitator superfamily (MFS) of integral membrane transporter proteins known to confer resistance to various antibiotics and toxins in fungi and bacteria. We propose that $C F P$ encodes a cercosporin transporter that contributes resistance to cercosporin by actively exporting cercosporin, thus maintaining low cellular concentrations of the toxin.
\end{abstract}

Additional keywords: drug/proton antiporter.

Members of the fungal genus Cercospora are pathogens of a variety of economically important crops including soybean and maize. At least 23 Cercospora spp. (Assante et al. 1977) produce the host nonspecific polyketide toxin cercosporin. Cercosporin, blood red in color, is a lipophilic, 4, 9hydroxyperylene-3, 10-quinone derivative with a molecular

Corresponding author: Robert G. Upchurch

E-mail: Greg_Upchurch@ncsu.edu

Current address of Terrence Callahan: Lake Erie College of Osteopathic Medicine, Erie, PA 16509, U.S.A.

Current address of Maura Meade: Department of Biology, Allegheny College, Meadville, PA 16335, U.S.A.

Current address of Mark Rose: Novartis Seeds, Inc., Research Unit, Research Triangle Park, NC 27709, U.S.A.

Nucleotide and/or amino acid sequence data of $C F P$ can be found at the GenBank data base as accession number AF091042.

This article is in the public domain and not copyrightable. It may be freely reprinted with customary crediting of the source. The American Phytopathological Society, 1999. weight of 534 (Lousberg et al. 1971; Yamazaki and Ogawa 1972; Okubo et al. 1975). Several observations suggest that cercosporin is a pathogenicity factor, including the finding that UV-induced, cercosporin-deficient mutants of C. kikuchii are nonpathogenic on soybean (Upchurch et al. 1991). Cercosporin production is induced by light (Lynch and Geoghegan 1979; Jenns et al. 1989; Ehrenshaft and Upchurch 1991; Rollins et al. 1993) and the toxin itself is light activated (Daub 1982a). In the light, cercosporin is converted to an electronically excited (triplet) state that can react with molecular oxygen by direct energy transfer to yield singlet oxygen (Daub and Hangarter 1983). Singlet oxygen is a highly reactive oxygen species damaging to cell membranes as well as other cellular structures. Singlet oxygen-catalyzed peroxidation of membrane lipids can lead to loss of membrane integrity, cytoplasmic leakage, and eventually cell death (Macri and Vianello 1979; Daub 1982b).

Because cercosporin appears to be a pathogenicity factor, developing ways of suppressing cercosporin production or engineering cercosporin resistance in plants are plausible strategies for combating diseases caused by Cercospora spp. Implementing these strategies requires a greater understanding of the molecular genetics of cercosporin biosynthesis and mechanisms of cercosporin resistance. Because cercosporin production is induced by light, work in our laboratory previously focused on the isolation of cDNAs corresponding to mRNAs exhibiting light-enhanced transcript accumulation in the expectation that one or more would be involved in cercosporin metabolism (Ehrenshaft and Upchurch 1991). Of six cDNAs isolated, LE6 (now known as CFP [cercosporin facilitator protein]) was the first chosen for targeted disruption analysis since its corresponding transcript showed the greatest light induction (20-fold) and a temporal expression pattern paralleling cercosporin accumulation. Here we report sequence analysis of $C F P$ and characterization of its function derived from an examination of $C F P$ disruption mutants.

\section{RESULTS}

Sequence analysis of the $C F P$ gene.

A 1.9-kb cDNA from plasmid pCFP was sequenced as was the 6.5-kb EcoRI insert of the genomic DNA clone pgCFP (a 3,312-bp portion of which is shown in Figure 1). A compari- 
son of the cDNA and genomic sequences indicated that $C F P$ contains three introns of 52, 50, and $49 \mathrm{bp}$ interrupting an open reading frame $(\mathrm{ORF})$ of $1,821 \mathrm{bp}$. These introns contain characteristic $5^{\prime}$ and $3^{\prime}$ splice junctions and an internal lariat consensus sequence observed in other filamentous fungi (Edelmann and Staben 1994). The region around the suspected ATG start site (codon 1174) reveals sequence similarity to Kozak sequences typically found at the translational start site of fungi and other eukaryotes (Edelmann and Staben 1994).

Translation of the 1,821-kb CFP ORF predicts a protein of 607 amino acids with a molecular mass of $65.4 \mathrm{kDa}$, an acidic pI of 5.08, and an unusually large number of cysteines (13 residues). BLAST (Gish and States 1993) searches of protein data bases indicate CFP is similar to major facilitator superfamily (MFS) drug resistance transporter proteins (Paulsen et al. 1996b), particularly those with 14 transmembrane segments (TMSs), representatives of which are shown in align- ment (Altshul et al. 1990) in Figure 2. This group, within the MFS, contains transporters or efflux "pumps" that mediate resistance to structurally diverse, typically hydrophobic drugs and toxins, some of which, like cercosporin, are polyketides. Consistent with its sequence similarity to integral membrane MFS transporters, CFP is highly (49\%) hydrophobic (Fig. 3). Interestingly, CFP is predicted to have only 13 TMSs by the program TMpred (Hoffman and Stoffel 1993). Nevertheless, the existence of a fourteenth TMS (double underlined in Figure 3) is suggested by the greater overall similarity of CFP to MF transporters with 14, rather than 12, TMSs and by CFP's possession of conserved motifs (D1, H, E, and F) diagnostic of MF transporters with 14 TMSs (Paulsen et al. 1996b).

Disruption of CFP and Southern analysis of CFP mutants.

To determine whether $C F P$ plays a role in cercosporin metabolism, $C F P$ (Fig. 4A) was disrupted in wild-type $C$.

Cla I ATCGATGATCTGIGCACGGCCACGTTGTCGGTOCACACIGSCGAGGCAGOCTATAAGATATTGTTOCTCTOCATCCAAGCAATGCGGAGAACCTGGTGTC ACTCATOGCAGAGGCTGTGAAGACCTAATGCCTAATCCCTOCACTACACAGGTGOOGAGAACOCTTCGGCCTCTTTCGAACAGCOGAGTGACAGTGCOCA GOCTTATGTGCTCCACCTTCCTGOCCTCGACCCATCTTCTCGGACCAAGACCCACCTCAATCTATCGATGAAAGATGTGAACAGTCTGCAGOCCAAGATC

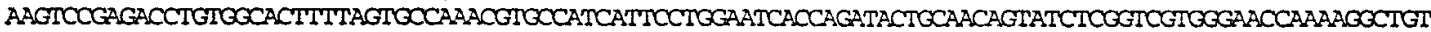
ACOGATATGITCGGAATACTCTGCTGTOCCCATGCATCACGGCTTAGAGOCATCCACGTTGCGGGICTGGGGA CCAAGGCAAAGOCAGACAATAGGCTCG CAGGTCTCTATCATCATCTACGACCCATCCGOGATGSGAGACTCTTTGGCGAGGTAOCGTGAACCGATGCATGAGCITGCAATCGTTGCGATTGOCTAAT TGAAGGCGCOCGGTTGTGTCGICCATATTAGCCAACAOCGTAATACTTCGACCATGCAGCAGITACTGGCCTIGATACTTTGTAOCGGTATGTCCTOCAC TOCCAACGATCTTCCTCOCCACACOCTTCATTTCCGAACATTTCTTCGTCACATCTATTTTCTTTGOCACACOCAAGAOGTIGAOCTCTCCATGTATTCG ATCGTAAGTACCTGICCTGAGGGCATATATTGCOCCQCTGATGCCTAAGGCATAGACOCATTTGAAAACCGTGCCATTCATTCATTOGGCGAAAOGCTTG

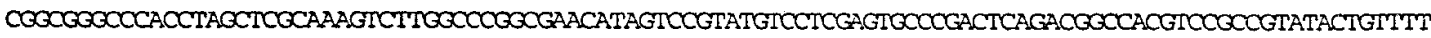
CGATCTACGSCAATAGGTTCGTCATCGAAAAATCGCAGOGAGATCGTTCAGITCGCGCAATTCCACGIGGIAGGTGGGCCGCTGATAGTCTCAGAAAGAA AACATAAAGAGGTAGOGGCCGTCGAATGAGITCCCTCATAGCAGTCTGGACCGOCTACTTTOCATACATTGACAATGACGAGCCCAGCGCGATCAADOCA

$$
\begin{array}{lllllllllll}
M & T & S & P & A & R & S & T
\end{array}
$$

TACTGATACAGAGTCTCACGACGTCGTAAAGGCGACTCGGAATCGAAACTOGAACTGGAGCACAGCGATTCGGATAATCAAGATGAGAGTCCAACGCT H T D AAGITGGCGGAAGCTCCTGAAGCCAAGCCAGAAGAGATGAAGAACTCAATGATCAAGCCGAGAGGTACATCTGCGGCTGGCCTCTGGTATTTCTCTTGT $\begin{array}{llllllllllllllllllllllllllllllllll}K & L & A & E & A & P & E & A & K & P & E & E & D & E & E & L & N & D & Q & G & E & R & Y & I & C & G & W & P & L & V & F & L & L\end{array}$ TAGCCATGGTCTCCACAGTCTTCATTGICGCTTTGAGCAACACCATCATCAOCACAGCAATCOCOGCCATCACAACAGCGTTCAATAGTACCCGAGATAT $\begin{array}{llllllllllllllllllllllllllllllllll}L & A & M & V & S & T & V & F & I & V & A & L & S & N & T & I & I & S & T & A & I & P & A & I & T & T & A & F & N & S & T & R & D\end{array}$

TOOCTGGTACAACTCTGGAGAAGCTCTTOCAGCCALTOCCTTCCAACTACCTTTCGOCCGACCGTATCTCTTGATGGACCTGAAGTGGACTTTCCTCGTC

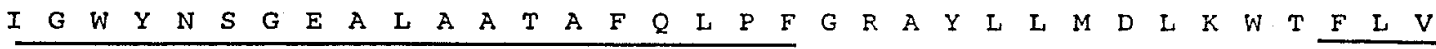
TCACTGOCCTTATATCTGATCGGCAGCCTGATCTGIGGIGTGGCAAACTCTTCTGAGCTICTCATITITIGGCCGATCGATTGCAOGAGTTGOCAACOCTG \begin{tabular}{lllllllllllllllllllllllllllllllllll}
$S$ & $L$ & $A$ & $L$ & $Y$ & $L$ & $I$ & $G$ & $S$ & $L$ & $I$ & $C$ & $G$ & $V$ & $A$ & $N$ & $S$ & $S$ & $E$ & $L$ & $L$ & $I$ & $F$ & $G$ & $R$ & $S$ & $I$ & $A$ & $G$ & $V$ & $G$ & $N$ & $A$ \\
\hline
\end{tabular} GCGTCTTCGCTGCCGTGTTCATCATTATTGCTCGAAACGITCCICTGCGGAAACGCGCACTTTATGCTGGATTGGITGGAGCGACTTTIGCCATTGCTGC $\begin{array}{llllllllllllllllllllllllllllllllllll}G & V & F & A & G & V & F & I & I & I & A & R & N & V & P & L & R & K & R & A & L & Y & A & G & L & V & G & A & T & F & A & I & A\end{array}$ TGTGCTGGGACCIGTCCTGGGIGGTATCTTTALTGACCGTATTAGCTGGAGGTGGIGITGTACAGTAAGTCTCTAGAACCCGTCCACTTTATTCCGITC $\begin{array}{lllllllllllllllllllllll}A & V & L & G & P & V & I & G & G & I & F & T & D & R & I & S & W & R & W & C & L & Y & \text { Intron } I\end{array}$ ATIGACACITTTCAACAGITAACCTGCCTATCGGAGCIGIACGIGTCGCAATCATCATATTCCTCCTTCCATCTCGICCTGGCGAAAAGGAGCAGAAGT $\begin{array}{lllllllllllllllllllllllllllll}I & N & L & P & I & G & A & V & R & V & A & I & I & I & F & L & L & P & S & R & P & G & E & K & A & A & E & V\end{array}$

Fig. 1. Genomic DNA sequence of $C F P$ and its flanks. ClaI and HindIII restriction sites used in construction of $C F P$ disruption vectors are indicated. Deduced 607 amino acid sequence of cercosporin facilitator protein (CFP) is presented below genomic sequence. TM domains predicted by TMpred program (Hoffman and Stoffel 1993) are indicated with a single underline; TM domain predicted by sequence similarity to 14 TM domain MF transporters is double underlined. Introns, identified by a comparison of genomic and cDNA sequences, are shown as numbered gaps in the translation. 
kikuchii strain PR. This was done by transforming PR with pg $\Delta$ CFP::BAR (Fig. 4B) and pgCFP::UIDA + pBPIT (Fig. 4C). Three transformants, identified by Southern analysis, contained $C F P$ disruptions resulting from double crossover integrations of a single copy of the disruption construct within $C F P$ without other ectopic integrations (Fig. 4D). CFP disruptants Bar-1 and Bar- 2 were produced by $\operatorname{pg} \triangle \mathrm{CFP}: \mathrm{BAR}$ transformation while $C F P$ disruptant Gus-3 was produced by co-transformation with pgCFP::UID + pBPIT. $C F P$ disruption was further verified by Northern (RNA) analysis; $C F P$ transcript was not detected in RNA isolated from any of these three transformants grown under conditions inducing CFP transcription in PR (M. S. Rose, unpublished results).

\section{Cercosporin production of $C F P$ disruption mutants.}

The amount of cercosporin present in 4-day-old potato dextrose broth (PDB) cultures of light- and dark-grown PR and light-grown cultures of $C F P$ disruptants was measured (Table 1). Bar-1, Bar-2, and Gus-3 produced less than $5 \%$ of the cercosporin produced by light-grown PR whereas dark-grown PR produced $11 \%$ of this amount.

\section{Cercosporin sensitivity of $\boldsymbol{C F P}$ disruption mutants.}

Sensitivity of the disrupted strains to cercosporin was determined by measuring radial growth of the strains on medium containing and lacking cercosporin (Table 2). When grown in the light on medium containing $10 \mu \mathrm{M}$ cercosporin, radial growth of Bar-1, Bar-2, and Gus-3 was reduced by 42 to $47 \%$ relative to their growth on medium lacking cercosporin whereas PR growth was only minimally reduced. Growth inhibition by cercosporin was not observed when strains were grown in the dark (data not shown).

\section{Complementation of $C F P$ disruption mutant Gus-3.}

Genetic complementation was used to further verify that disruption of $C F P$ causes a reduction in cercosporin production and resistance. Gus-3, which is brown-yellow in appearance and does not produce visible amounts of cercosporin (Fig. 5A) was transformed with pgCFP + pUCHI. pUCHI contains the selectable marker $h p h$, which confers resistance to hygromycin B. Hygromycin-resistant transformants were selected and polymerase chain reaction (PCR) was used to identify two transformants (10-1 and 10-11) containing both intact and disrupted copies of CFP indicative of Gus-3 strains transformed with pgCFP (Fig. 5B and C). This was accomplished with the intact, $C F P$-specific, primer pair O3-O2 (see Figure 4A), which amplified a 2,503-kb fragment from the genomes of PR, 10-1, and 10-11, but not Gus-3 (Fig. 5B), and disrupted $C F P$-specific primer pair O3-Otct (see Figure 4C), which amplified a 1,725-kb fragment from Gus-3, 10-1, and

Fig. 1. (continued from preceding page)

GOCGSCGOCGAATACCGITGGAGTGCTGGTCGIGLCGITGCTGTACTGGTOGTCTTCGCCGTCAGCTTCATCGCATGGCTGGTTCTGCAATACTICCAAG

$\begin{array}{llllllllllllllllllllllllllllllllllll}G & G & G & E & Y & R & W & S & A & G & R & V & V & A & V & L & V & V & F & A & V & S & F & I & G & W & L & V & L & Q & Y & F & Q\end{array}$

GCGACGAAGCCACACTGCCATTTAACGTTGCAAAACAGCGTACCGTTGGTGGIGCCTCTATCTACACTCTGCATCTGAGCGCCGCATTIGGACTCGICAT

$\begin{array}{llllllllllllllllllllllllllllllllllll}G & D & E & A & T & L & P & F & N & V & A & K & Q & R & T & V & G & G & A & S & I & Y & T & L & H & L & S & A & A & F & G & L & V & I\end{array}$

ATACTATCTGCCTCTCTGGIGAGITGATTCATGAGCATGCACTGGOCTCACGAACTGACATTATGA.GGTTICAAGCAGTACGATCTGACAGTGCCGAAG

$\begin{array}{lllllllllllllllll}Y & Y & L & P & L & W & \text { Intron } 2 & E & A & V & R & S & D & S & A & E\end{array}$

CTOCTGSTCTCAAGCAACTTGGCATCGICATCTCGCTCACTCTCTOGTCAATTGCAGCTOGCGGTGCTGTTGTAAAAATAGCATATTACTATCCTTTCAT $\begin{array}{llllllllllllllllllllllllllllllllll}A & A & G & L & K & Q & L & G & I & V & I & S & L & T & L & S & S & I & A & A & G & G & A & V & V & K & I & G & Y & Y & Y & P & F\end{array}$ TTACGCCGGAACGGTCTTATGCAOCATCGOCTCTGGCTTGCTTTACACGATCACACTCGATACACCGCAATGGGATATGTAAGTAATCGAGCTCCGACTG $\begin{array}{lllllllllllllllllllllllllll}I & Y & A & G & T & V & L & C & S & I & G & S & G & I & L & Y & T & I & T & L & D & T & P & Q & W & D & \text { Intron } 3\end{array}$

AATPTGAACATTTCTAACGCATGACAGTATCGGTTATTCGATCGTATTCGCCATIIGGAATCGOCGTCA.GTCTCGA.GCAATCCAACGTIOCTGTCCAGACT

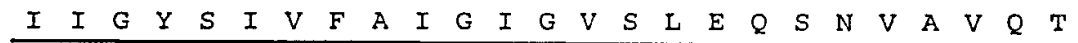
Hind III

GTCCTOCCCGATOCTCAGATACCAGCAGGAACAAGTITGITCTGITCGTCCGACTACTTGGATCAGCAATCCCCGGACCCATCGGACAGAGIGTACTCC

\begin{tabular}{llllllllllllllllllllllllllllllllll}
$V$ & $L$ & $P$ & $D$ & $A$ & $Q$ & $I$ & $P$ & $A$ & $G$ & $T$ & $S$ & $L$ & $V$ & $L$ & $F$ & $V$ & $R$ & $L$ & $L$ & $G$ & $S$ & $A$ & $I$ & $P$ & $G$ & $P$ & $I$ & $G$ & $Q$ & $S$ & $V$ & $L$ \\
\hline
\end{tabular}

AGACAACACITGCCAGTAGGCTAGOGACTGAGGTCOCAGAGCAAGCATATGGIGGTACCGGAGCAACTGAAATCCGCTCAAAGCTCGA.CAACATTTTTIGG

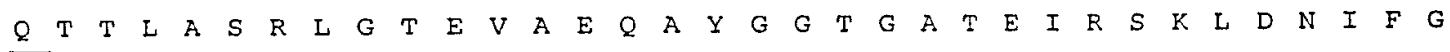
AGCTGGCACACCTGAAGCTCGAGATGCCCTTGACGCTIICAACGATTCTGIGACGAAGATCTTCATGGTCOCAATCATAGICTCATGICTGAGIGCGCTG

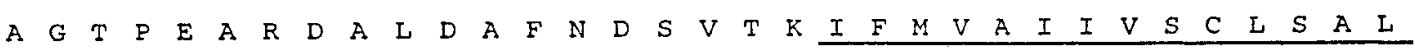
CCICTTCCCCTCATCGAGCTCAAGAOCGTCAAGCGTGAGAAACGAGACACGAAGACGCCAAAGA.GGCAAGAAAACTALTGGGACGACGCGIGAGATAG

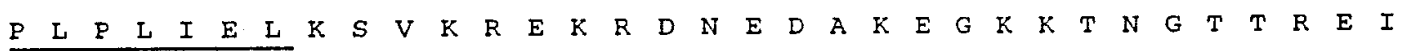
AAGATCCAGAGAAGGOGCAGAGTGCAGAGATCGIGGOCAAAGCAGTGTGAGATGIGGCATCAGACCGMGGACGATITITATAGACATTGTAGCGAGCTGT

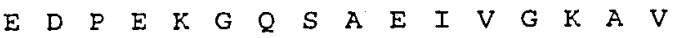
TACGACTAACGCATGTACCCAACACAGTGIGIGCCICAGAGGCAATAGAGCT TTGACGACATAATAALCAAGAATTTTAATGGCTACGAGTCCICTCAA AACCTCGCCGCA 3312 
10-11, but not from PR (Fig. 5C). Both 10-1 and 10-11 were observed to possess restored ability to produce cercosporin (Fig. 5A) and resistance to cercosporin similar to that of wildtype PR (data not shown).

\section{Virulence of $C F P$ disruption mutants on soybean.}

To assess virulence, susceptible soybean cv. Lee-68 was inoculated with $C F P$ disruptants Bar-1 and Gus-3, wild-type
PR, and CFP-complemented Gus-3 disruptants 10-1 and 1011. Symptoms were allowed to develop for 15 days (Fig. 6) In all cases $C F P$ disruptants displayed greatly reduced virulence relative to $\mathrm{PR}$ and the $C F P$-complemented disruptant strains (data not shown) were similar in virulence to PR. These results demonstrate that $C F P$ is required for wild-type virulence and are consistent with the function of cercosporin as a pathogenicity factor.

\begin{abstract}
CFP MTSPARSTHTDTESHDVVKSDSESKLELEHSDSDNQDEKS 40

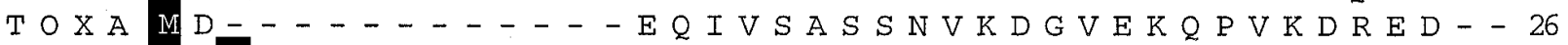

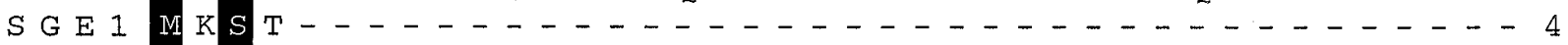
Q A C A M I S - - - . - - - - F F T K T T M M T K K R W T A $\ldots \ldots$

CFP NAKLAEAPEAKPEEDEELND G ERYICGWPLVFLLIAMV TOXA - - V V A N V V P H T P S L P K - - - I S L I S L F S I M S I G 57 SGEI $1 \ldots \ldots \ldots$. $\ldots \ldots \ldots$ L T C V I S L I L 16

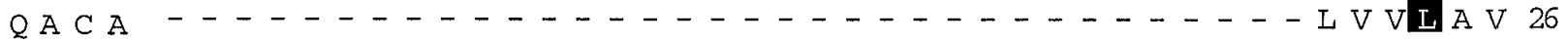
D1 I D $\mathrm{T}$ V X $\mathrm{N}$ VA I P

CF P TVFIVALSNTIISTAIPAIT TAFNSTRDIG-WYNSGEA IA 119 TOXA A A F L G A DATVVAVLTATLA Q E F H S D A V A - W Y A I Y L M 96 $S G E I$ T LFLA A L D IVIVVTLYDTIGIKFHDFGNIG-WLVTG YA L S 55

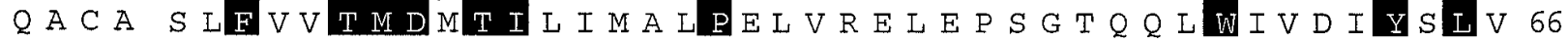

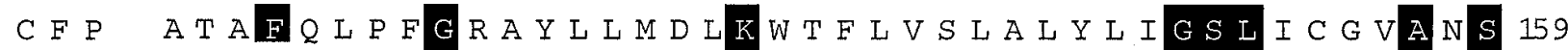
TOXA SGTTQPLFGKLYNEFS PKWLFITCLIVLQLGSL V C A LARI 136 SGE 1 NAVFMILWGRIAEILGTKECLMISVIVFEIGSLISALSNS 95

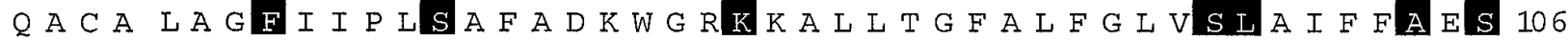

CFP SEILIFGRSIAGVGNAGVFAGVFIIIARNVPL-RKRAI Y A 198 TOXA SPTFIVGRAVAGIGAGGILSGAINIVALIVPL-H RAA F T 175

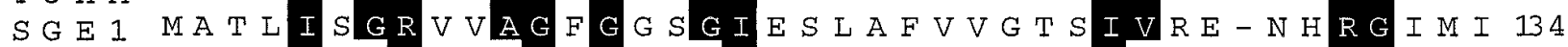
QACA AEFVIAIRFIIGIAGALIMPTTLSMIRVIFE P R ERATAI 146

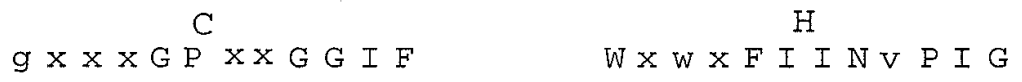
$\mathrm{H}$

CFP GLVGATFAIAAVLGPVLGGIFTDR I SWR W C Y I N I P I G A V 238 TOXA GMIGAIECVALIIGPIIGGAIADNIGWR W C F W I N L P I G A A 215 SGE 1 TALA I S Y V I A E G V P F I G G A F E H L SWR W C F Y I N L P I G A F 174 QACA AVWSIASSIGAVFGPIIGGALLEQFSWH SA LI NVIFAII 186 CFP RVAIIIF- - - - - - - LLPSRPGEKA- - - A EVKDLSW 263 TOXAVCAILIF_- - - - - - FFHP PRSTYS - - - A S G P R S 240 SGE 1 A F IILAFCN T S E P H Q K M W P SKIKKIM N Y Y G E L K A S F 214

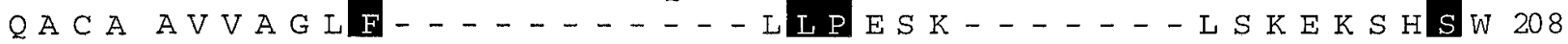
$\mathrm{E}$ $D \times \times G \times \times L$

CFP WQ - - - F F L K L N P F S A L L G S L T F F L A L Q W G G E Y W 298 TOXA SE - - - I L G N L Y I G A GMIISS LVCLSLALQWG G T Y K W 275 SGE 1 WKNTEEVIVFKLDMVGIILSSAGF T L L MLGLSF G N N F P W 254 QACA _.......... DI PSTILSIAGM - - I GLVWSIKEF SK 232

Fig. 2. Alignments of deduced amino acid sequences of CFP from Cercospora kikuchii PR, TOXA of Cochliobolus carbonum (GenBank L48797), SGE1 of Saccharomyces cerevisiae (GenBank 111640), and QACA of Staphylococcus aureus (GenBank X56628) produced with the CLUSTAL algorithm employed by DNAStar. Shaded amino acids are identical or functionally conserved in three or four aligned proteins. Overall amino acid sequence similarity between CFP and TOXA, SGE1, and QACA is 47, 40, and 34\%, respectively. Consensus sequences of motifs diagnostic for 14 TMS MF transporters (D1, H, E, and F) (Paulsen et al. 1996a) are indicated above translations. Motif C, common to both 12 and 14 TMS MF transporters, is also indicated. 


\section{DISCUSSION}

Since cercosporin production in $C$. kikuchii is induced by light, we had hypothesized that transcription of genes involved in cercosporin metabolism would also be light induced. Consequently, we cloned cDNAs of transcripts that accumulated to higher levels in the light than in the dark (Ehrenshaft and Upchurch 1991). This led to the identification of several light-induced genes. Of these, one now designated
CFP displayed the greatest light induction and a temporal expression pattern paralleling cercosporin accumulation. A subsequent study indicated $C F P$ to be a single-copy gene mapping to the largest $(5.5 \mathrm{Mb})$ chromosome in $C$. kikuchii (Hightower et al. 1995).

Here we report that targeted disruption of $C F P$ has multiple effects on cercosporin metabolism. Though not diminished in growth or viability, CFP disruptants produce $95 \%$ less cercosporin than does the wild type. Consistent with earlier studies

Fig. 2. (continued from preceding page)

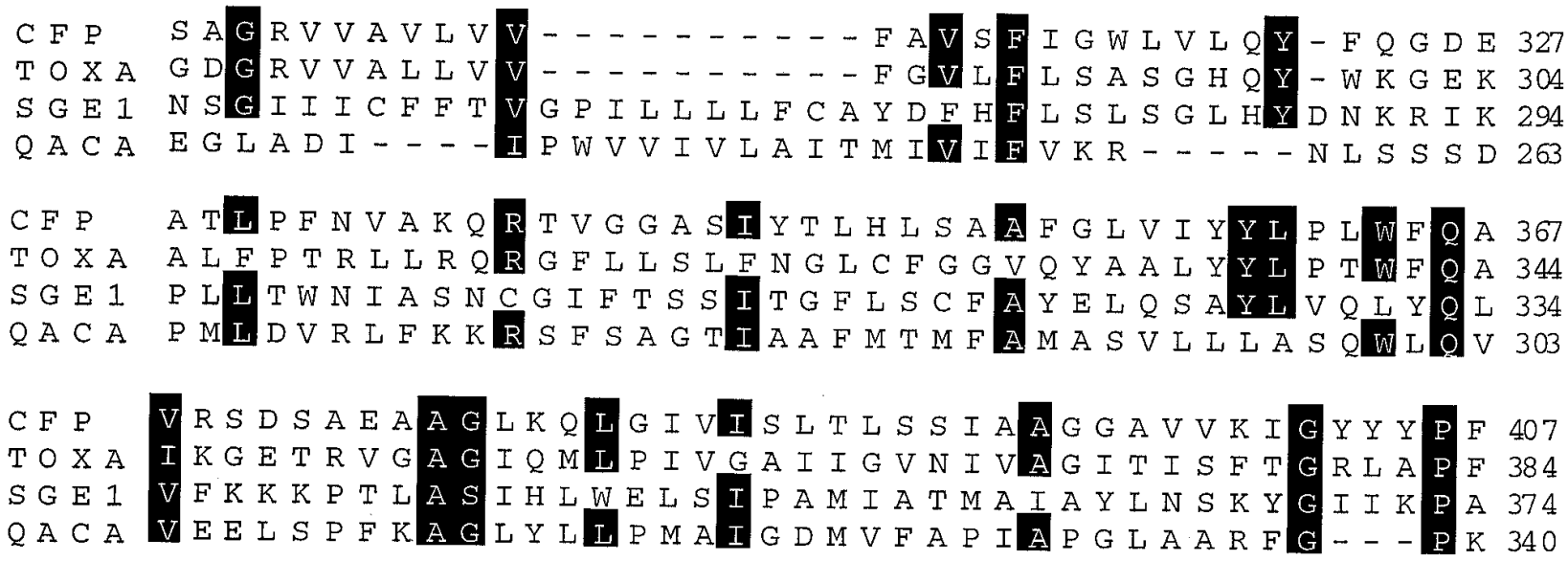

C F P IYA T TLCSIGSGLLYTITLDTPQW-DIIG Y S V F A I I G 446 TOX A IVIA TVLASVGSGLLYTFT P TKS Q A - R I I G Y Q L I Y G A G S G 423 $S G E 1 I V F G-V L C G I V G S G I F T L I-N G E I S-Q S I G Y S I L P G I A F G 411$ QACAIVIPSGIGIAAIGMFIMYFFGHPLS Y S T MALALILVGAGM 380

CFP VSLEQSNVAVQTVLPDAQIPAGTSLVIFVRI- - L G S I PG 484 TOXA A G Q QAFIGA QA A D P A D T Y A S A S L L M - - - - N S M S 457

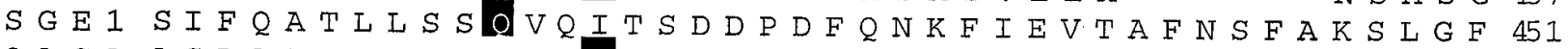
QACA ASIAVA- - SALIMLETPTSKAGNAAAVEESMYDIGNVFGV418

CFP PIGQSVLQTTL- - - A ARIGTEVAEQAYGGTGATEIRSK 519 TOXA VITLCVCQNIF- - - T TRI - NALTEVLPGVTKETLQS G 490

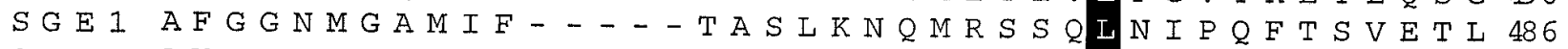
QACA AVLGSLSSMLYRVFIDISSFSSKGIVGDLAHVAEESVVGA 458

CFP IDNIFGAGTPEARD-AIDAF-NDSVTKIFMVAIIVSCLSA 557 TOXA FAFLRSTLTPAEF GVAIQTF-NSA I Q D A F L V A IVI S CA SV 529 SGE 1 LA Y - S TEH Y D P Q S S L S K F N TA I H D V F Y CA - L G C - - 519

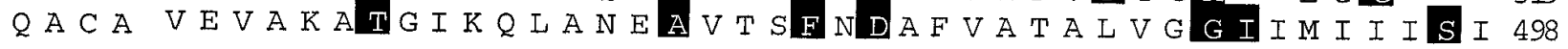

CFP LPLPLIELKSVKREKRDNEDAKEGKKTNGTTREIEDPEKG 597 TOXA LGWPFLSWAS VKG QKK M K

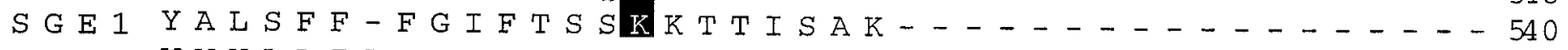

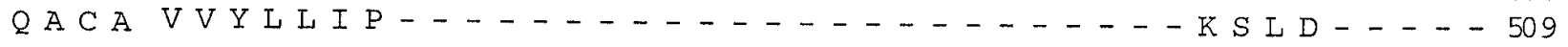

CFP QSAEIV GKAV 607

TOX A

SGE 1 - . - - K Q Q 543

QACA - - - I TKQ K 514 
that suggested that cercosporin is a pathogenicity factor, $C F P$ disruptants, presumably by virtue of their reduced cercosporin production, are greatly reduced in virulence to soybean. Furthermore, disruptants are sensitive to cercosporin when it is exogenously supplied. That cercosporin production, resistance, and virulence phenotypes of the $C F P$ disruptants are solely attributable to $C F P$ disruption was confirmed by genetic complementation of $C F P$ disruptant strain Gus-3 with a wild-type copy of $C F P$ that restored cercosporin production, virulence, and resistance.

Sequence analysis of CFP indicates that it encodes a protein similar to several members of the MFS of transporter proteins (Marger and Saier 1993; Paulsen et al. 1996b), particularly those in the drug resistance family (Fig. 3), examples of which include TOXA, the putative HC-toxin transporter from Cochliobolus carbonum (Pitkin et al. 1996), SGE1, which confers crystal violet resistance in Saccharomyces cer- evisiae (Ehrenhofer-Murray et al. 1994), QACA, which confers multidrug resistance in Staphylococcus aureus (Paulsen et al. 1996a), and TRI12, the recently discovered putative trichothecene transporter in Fusarium sporotrichioides (Alexander et al. 1997). Members of this family are known to confer resistance to drugs and other toxins through an active export mechanism that is driven by proton motive force. While most of these transporters (including SGE1 and QACA) are involved in exporting toxins encountered by the organism in its external environment, others appear to export endogenously synthesized toxins (TOXA, TRI12, and now CFP).

The drug resistance family of the MFS includes two evolutionarily distinct clusters each with unique consensus motifs and topologies; those with 14 TMSs and those with 12 TMSs (Paulsen et al. 1996b). Although computer analysis predicted 13 TMSs in CFP, CFP has all motifs (D1, H, E, F in Figure 2) identified as diagnostic of 14 TMS MF transporters, and lacks

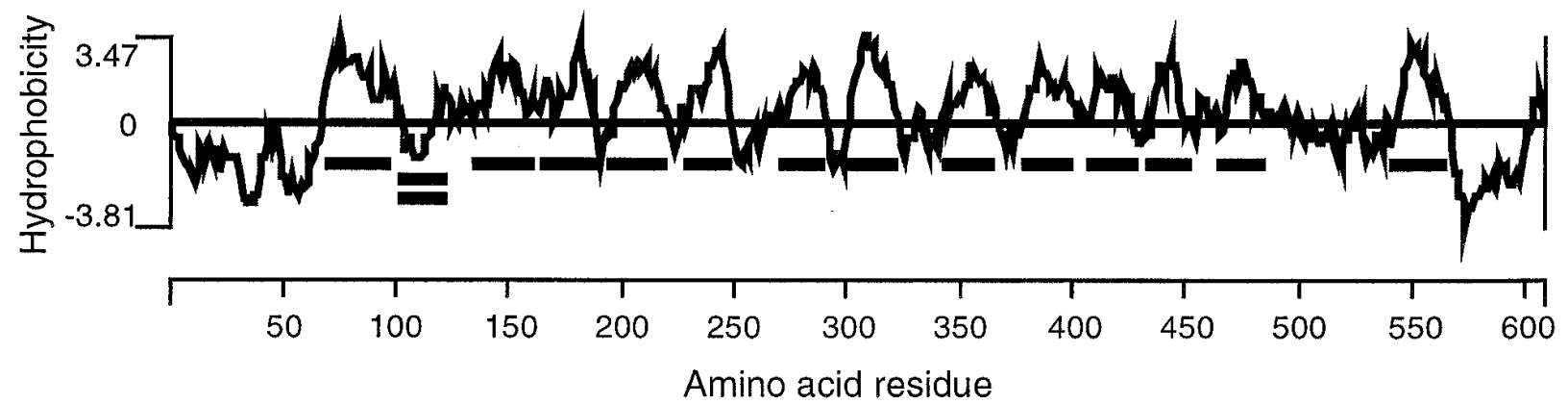

Fig. 3. Hydrophobicity plot of cercosporin facilitator protein (CFP) (Kyte and Doolittle 1982). Hydrophobic amino acids are plotted as positive values; hydrophilic amino acids as negative values. TM domains predicted by TMpred program are indicated with a single underline; TM domain predicted by sequence similarity to $14 \mathrm{TM}$ domain MF transporters is double underlined.

A

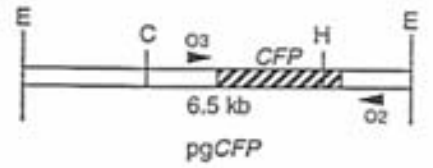

B

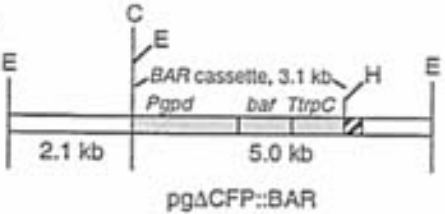

C

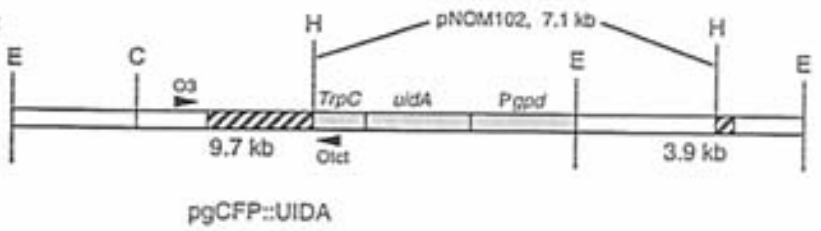

D
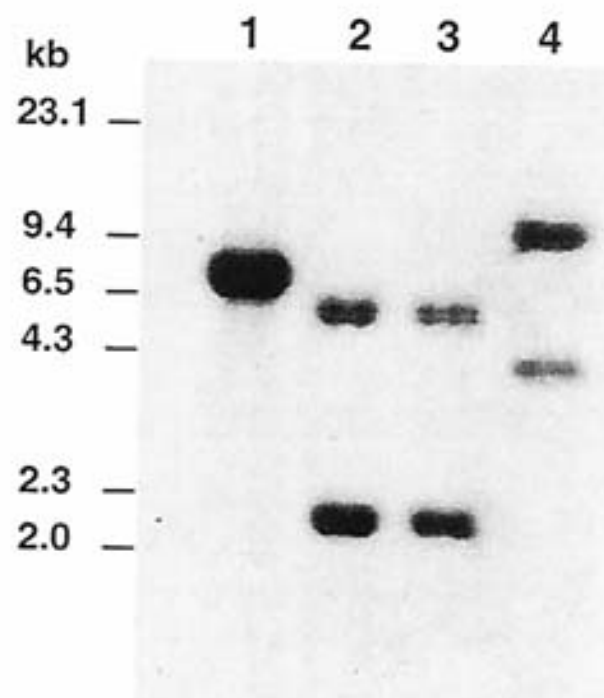

Fig. 4. Constructs used to disrupt $C F P$ and Southern analysis of wild- type and three disruptant strains of Cercospora kikuchii. A, Restriction map of the 6.5-kb EcoRI genomic fragment containing CFP excised from pgCFP. Arrowheads indicate relative positions of polymerase chain reaction (PCR) primers $\mathrm{O} 2$ and O3. B, Restriction map of pg $\triangle \mathrm{CFP}: \mathrm{BAR}$ (minus pGEM3zf ${ }^{+}$vector) used to produce $C F P$ disruption strains Bar-1 and Bar-2. C, Restriction map of pgCFP::UIDA construct used to produce CFP disruption strain Gus-3. Arrowheads indicate positions of PCR primers O3 and Otct. D, Southern analysis of EcoRI-digested genomic DNA probed with the radiolabeled 6.5-kb EcoRI fragment from pgCFP. Lane 1, C. kikuchii strain PR; lane 2, Bar-1; lane 3, Bar-2; and lane 4, Gus-3. Consistent with predictions for CFP disruptants, the wild-type 6.5-kb EcoRI fragment hybridizing with the CFP probe (lane 1) is replaced in transformants Bar-1 and Bar-2 by 2.1- and 5.0-kb bands (lanes 2, 3) and in Gus-3 by 3.9- and 9.7-kb bands (lane 4). 
those associated exclusively with 12 TMS MF transporters. For this reason and because of CFP's greater overall similarity to 14 TMS transporters we propose that CFP possesses 14 TMSs and is responsible for cercosporin export in $C$. kikuchii-hence the name cercosporin facilitator protein. CFP also possesses motif C (Fig. 2), which is common to both 12 and 14 TMS MF drug/proton antiporters but not found in MF symporters. CFP is the first putative MF transporter of a fungal polyketide to be described.

Since sequence analysis indicates that CFP is an MFS transporter protein its role in cercosporin production appears to be regulatory rather than biosynthetic. The low levels of cercosporin accumulating in $C F P$ disruptants (less than $5 \%$ of wild type) suggest that functional CFP is required for a fully functional cercosporin biosynthetic pathway. Hypothetically, when the cellular cercosporin concentration reaches a level above a critical theoretical threshold in the absence of export, as may happen in $C F P$ disruptants, biosynthetic enzymes may be inhibited by end product (cercosporin) feedback. Alternatively, the transcription of cercosporin biosynthetic pathway genes may be down-regulated in response to perceived intracellular accumulation of cercosporin. Such a phenomenon occurs in Pseudomonas syringae, in which mutation of the gene encoding the syringomycin ABC-type drug transporter SyrD down-regulates the transcription of syringomycin biosynthetic genes (Quigley et al. 1993). Interestingly, SyrD mutants display a phenotype similar to that of $C F P$ disruptants; they produce much less toxin (syringomycin) than does the wild type and are sensitive to it when it is exogenously supplied. SyrD disruptants are also dramatically reduced in virulence.

The amino acid sequence of CFP has 13 cysteine residues. Proteins with as few as five cysteine residues have been considered "cysteine-rich" (Pineiro et al. 1994). The relatively high cysteine content of CFP may suggest additional aspects of function. Plant proteins containing five or more cysteine residues have been implicated in the modulation of redox po-

Table 1. Cercosporin production by wild-type PR and CFP disruption strains

\begin{tabular}{lcc}
\hline Strain & $\begin{array}{c}\text { Cercosporin } \\
(\mathbf{n m o l} / \mathbf{m g} \text { dry wt) }\end{array}$ & $\begin{array}{c}\text { Cercosporin } \\
\text { relative to PR Lt } \mathbf{( \% )}^{\mathbf{b}}\end{array}$ \\
\hline PR Lt & $30.1 \pm 10.4$ & 100 \\
PR Dk & $3.3 \pm 1.4$ & 11 \\
Bar-1 Lt & $0.8 \pm 0.5$ & 3 \\
Bar-2 Lt & $1.3 \pm 0.8$ & 4 \\
Gus-3 Lt & $1.2 \pm 0.9$ & 4 \\
\hline
\end{tabular}

${ }^{a}$ Mean and standard error for two experiments.

${ }^{\mathrm{b}} \mathrm{Lt}=$ grown in continuous light for 4 days; $\mathrm{Dk}=$ grown in continuous dark for 4 days.

Table 2. Sensitivity of Cercospora kikuchii wild-type PR and CFP disruptants to cercosporin

\begin{tabular}{lccc}
\hline Strain $^{\text {a }}$ & $\begin{array}{c}\text { Colony diameter }(\mathbf{m m}) \\
\pm \text { cercosporin }^{\mathbf{b}}\end{array}$ & $\begin{array}{c}\text { Growth }(\%) \\
\pm \text { cercosporin }\end{array}$ & $\begin{array}{c}\text { Growth (\%) } \\
\text { inhibition }\end{array}$ \\
\hline PR & $14.1 \pm 0.8 / 14.4 \pm 0.7$ & 98.3 & 1.7 \\
Bar-1 & $8.0 \pm 0.8 / 15.0 \pm 0.5$ & 53.3 & 46.7 \\
Bar-2 & $8.1 \pm 0.9 / 15.0 \pm 0.8$ & 54.2 & 45.8 \\
Gus-3 & $8.5 \pm 0.9 / 14.8 \pm 0.9$ & 57.6 & 42.4 \\
\hline
\end{tabular}

${ }^{a}$ Wild-type C. kikuchii PR and CFP disruptant strains grown in continuous light for 4 days with and without $( \pm) 10 \mathrm{mM}$ cercosporin.

${ }^{\mathrm{b}}$ Mean and standard error for two experiments.
A

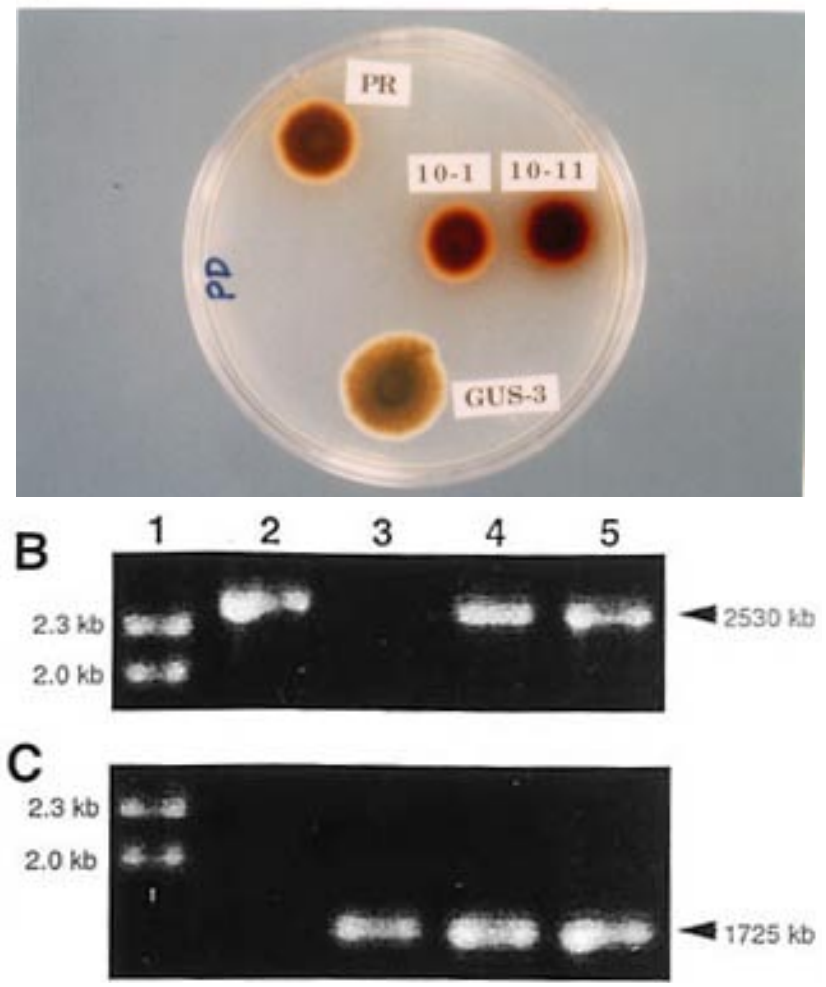

Fig. 5. Genetic complementation of the CFP disruptant Gus-3. A, Potato dextrose agar plate showing cercosporin production (red-brown pigment) by Cercospora kikuchii wild-type strain PR and CFPcomplemented strains $10-1$ and 10-11. Cercosporin was not visually detected in Gus-3 mycelium. B, Agarose electrophoretic gel showing polymerase chain reaction (PCR) products amplified from PR, Gus-3, 10-1, 10-11 (lanes 2-5, respectively), with primers $\mathrm{O} 2$ and $\mathrm{O} 3$, designed to detect intact CFP (see Figure 4C) Lane 1 is HindIII-digested lambda molecular weight markers. $\mathbf{C}$, PCR products amplified with primers $\mathrm{O} 3$ and Otct, designed to detect the disrupted copy of CFP engineered in transformant Gus-3 (see Figure 4D). Lanes are as in B.

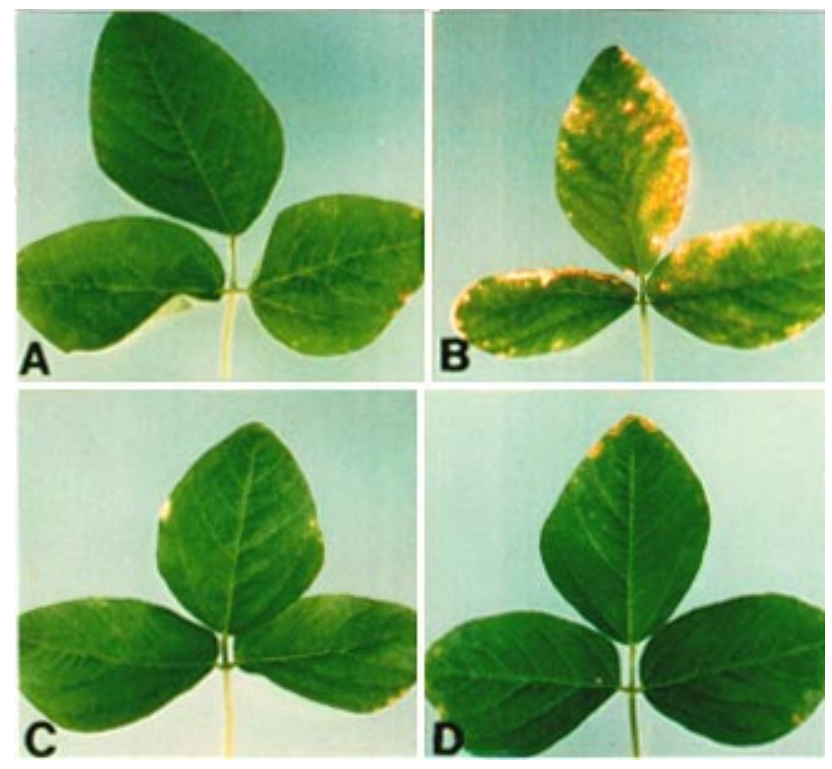

Fig. 6. Soybean cultivar Lee-68, 15 days after inoculation with (A) water, (B) wild-type C. kikuchii PR, (C) cercosporin facilitator protein (CFP) disruptant Bar-1, and (D) CFP disruptant Gus-3. 
tentials of various compounds (Pineiro et al. 1994). To date, however, there is no evidence for CFP involvement in cercosporin reduction. Even if the cysteine content of CFP has no connection to reductive capabilities, the high cysteine content of CFP and TOXA, which contains nine cysteine residues, merits further attention.

Genes encoding enzymes required for the biosynthesis of several fungal and bacterial toxins are clustered in the genomes of the producing organism. In several instances genes encoding toxin transporters have also been found within these clusters. For example, MF transporters TOXA (C. carbonum) and TRI12 (F. sporotrichioides) are clustered with the HC-toxin and trichothecene biosynthetic pathway genes, respectively, while the ABC transporter SyrD is clustered with the syringomycin biosynthetic pathway genes (Pitkin et al. 1996; Alexander et al. 1997; Quigley et al. 1993). Sequence similarity analysis of several kilobases of $C F P$-flanking DNA, however, has not revealed the presence of any genes known to be involved in polyketide metabolism, suggesting that the cercosporin biosynthetic genes are not closely linked to CFP (M. S. Rose, unpublished data).

This work, as well as research in Cercospora nicotianae, suggests that resistance to cercosporin in Cercospora spp. may be due to multiple mechanisms. A number of studies have described a strong correlation between reduction of cercosporin and cercosporin resistance (Daub et al. 1992; Leisman and Daub 1992; Sollod et al. 1992; Jenns et al. 1995) Recent work in C. nicotianae (Daub et al. 1998; Ehrenshaft et al. $1998,1999)$ identified two genes that complement cercosporin-sensitive mutants (Jenns et al. 1995; Jenns and Daub 1995). The first gene, SORl (singlet oxygen resistance), rescues five independently isolated mutants from sensitivity to cercosporin and other singlet-oxygen-generating photosensitizers to resistance. The second gene, CGRl (cercosporin resistance gene), restores cercosporin resistance to a mutant that is partially sensitive to cercosporin but is unaltered in resistance to other photosensitizers. Although mutations in $C R G 1$ and $C F P$ produce similar cercosporin-sensitive phenotypes, they are distinct sequences. The mechanisms by which SORI and $C R G 1$ contribute to cercosporin resistance remain to be clarified. We propose that CFP confers resistance by actively exporting cercosporin from the fungal cell. Although we have as yet no direct measurement of CFP-driven cercosporin efflux in C. kikuchii, such a mechanism is indicated by the structural similarity of CFP to MFS drug transporters and the phenotypic similarities of CFP and SyrD mutants. To further characterize the role of CFP in cercosporin resistance and to determine its utility as a source of transferable toxin resistance, we intend to express $C F P$ in other toxinsensitive organisms.

\section{MATERIALS AND METHODS}

\section{Fungal strains, culture conditions.}

Cercospora kikuchii wild-type strain PR was provided by J. B. Sinclair, University of Illinois, Urbana. C. kikuchii strains were grown in either PDB (Difco, Detroit, MI) or on potato dextrose agar (PDA) at $23^{\circ} \mathrm{C}$ under either continuous white fluorescent light (approximately $80 \mu \mathrm{E} \cdot \mathrm{s}^{-1} \cdot \mathrm{m}^{-2}$ ) or in darkness. Liquid cultures were shaken at $180 \mathrm{rpm}$ (Innova illuminated incubator shaker; New Brunswick Scientific, Edison,
$\mathrm{NJ}$ ) in 125-ml Erlenmeyer flasks containing $50 \mathrm{ml}$ of PDB. Dark-grown cultures were obtained by wrapping flasks with thick, plastic-lined, black cloth and aluminum foil. Pure cultures were maintained by hyphal tip transfer.

\section{Plasmids.}

pCFP, previously designated pcLE6 (Ehrenshaft and Upchurch 1991), contains a 1.9-kb cDNA of a full-length transcript cloned as an EcoRI-XhoI fragment in $\mathrm{pBSISSK}^{+}$ (Stratagene, La Jolla, CA). To obtain a genomic clone, a genomic library of $C$. kikuchii DNA was constructed in the cosmid vector pCKB4 (Upchurch et al. 1991) by standard techniques. Each clone was stored individually in the wells of microtiter plates. After replication of the clones to nitrocellulose filters, colony blots were made by standard techniques and probed with ${ }^{32} \mathrm{P}$-labeled insert DNA from pCFP. Analysis of the approximately 50-kb hybridizing cosmid indicated that a single $6.5-\mathrm{kb} E c o$ RI fragment contained the hybridizing DNA plus $5^{\prime}$ and $3^{\prime}$ flanking sequences. This fragment was subcloned into pGEM3Zf ${ }^{+}$(Promega, Madison, WI), resulting in pgCFP. Disruption plasmid pg $\triangle \mathrm{CFP}: \mathrm{BAR}$ is pgCFP in which the 2.5-kb ClaI-HindIII fragment containing the $5^{\prime}$ end of $C F P$ is replaced with the $3.1-\mathrm{kb} C l a \mathrm{I}-H i n d I I I$ BAR expression cassette subcloned from plasmid pNB1 (Upchurch et al. 1994). The BAR gene encodes phosphinothricin acetyltransferase, which enables transformed fungi to grow in the presence of the selective agent bialaphos (Straubinger et al. 1992). The 2.5-kb ClaI-HindIII genomic DNA deleted in pgCFP::BAR was demonstrated by Northern analysis to encode no other transcript but that of CFP (M. S. Rose, unpublished result). Disruption plasmid pgCFP::UIDA was constructed by gel purifying the $6.5-\mathrm{kb}$ EcoRI genomic DNA insert of pgCFP followed by treatment with T4 DNA ligase to circularize the fragment. Following heat inactivation of the ligase, the circular molecule was linearized with HindIII and ligated into the HindIII site of pNOM102. pNOM102 contains UIDA, which encodes a $\beta$-glucuronidase (GUS) able to cleave the substrate methyl umbelliferyl glucuronide (MUG) (Sigma, St. Louis, MO) to confer a $\left(\mathrm{GUS}^{+}\right)$fluorescent phenotype that can be visually scored (Roberts et al. 1989). pUCHI contains $h p h$, a gene encoding hygromycin phosphotransferase that enables transformed fungi to grow in the presence of the selective agent hygromycin B (Turgeon et al. 1987).

\section{Transformation.}

Transformation of C. kikuchii has been described (Upchurch et al. 1994). Transformants were selected on minimal regeneration medium with either 20 or $50 \mu \mathrm{g}$ of bialaphos or hygromycin B (Sigma, St. Louis, MO) per ml, respectively. Introduction of pgCFP into strain Gus-3 was by cotransformation with pUCHI. Introduction of gCFP::UIDA into PR was by co-transformation with the $B A R$ plasmid pBPIT (Straubinger et al. 1992).

\section{Nucleic acid manipulations.}

DNA restriction digests and Southern blot analyses were performed as described by Sambrook et al. (1989). The Geneclean II kit from Bio101 (La Jolla, CA) was used to purify DNA fragments from agarose gels. C. kikuchii genomic DNA was isolated from mycelium harvested from 5-day-old liquid cultures as described by Garber and Yoder (1983). Nitrocel- 
lulose or Nytran Plus membranes (Schleicher and Schuell, Keene, $\mathrm{NH}$ ) were used for nucleic acid blots following protocols supplied by the manufacturer. ${ }^{32} \mathrm{P}$-radiolabeled probes were made with the random priming oligolabeling kit from Pharmacia (Thousand Islands, CA).

\section{DNA sequencing and analysis.}

$\mathrm{p} C F P$ and $\mathrm{gCFP}$ were sequenced with the Sequenase kit supplied by U.S. Biochemical (Cleveland, OH). Custom primers for sequencing were supplied by Integrated DNA Technologies (Coralville, IA). Nested deletion clones also used for sequencing were made with Erase-a-base (Promega, Madison, WI). Sequence analysis and management software used included MacVector (IBI, New Haven, CT), DNASTAR (DNASTAR, Madison, WI) and Gene Works (IntelliGenetics, Mountain View, CA). Transmembrane sequences were predicted with TMpred (Hoffman and Stoffel 1993). Searches for sequence similarity in the NCBI data bases were performed with BLAST (Gish and States 1993; Altschul et al. 1990). The GenBank accession number for CFP is AF091042.

\section{PCR detection of $C F P$ complementation.}

PCR amplifications to detect intact $C F P$ contained genomic DNA from selected strains, $1 \times$ PCR buffer with $2 \mathrm{mM} \mathrm{MgCl}$ (Stratagene, La Jolla, CA), $240 \mathrm{nM}$ dNTPs, $200 \mathrm{nM}$ concentrations of primers "O2" (5'-GGATGATTTTGGAGAGCGA GAGCGAGTA-3') and "O3" (5'-ACGTGGTAGGTGGGC CGCTGATAGTC-3'), and $2 \mathrm{U}$ of Taq DNA polymerase (Stratagene). Detection of disrupted $C F P$ was as above except primer "Otct" (5'-GTAAGCGCCCACTCCACATCTCCA-3') was substituted for primer O2. Following an initial denaturation step of $95^{\circ} \mathrm{C}$ for $1 \mathrm{~min}, 35$ thermocycles of $94^{\circ} \mathrm{C}, 1 \mathrm{~min}$; $60^{\circ} \mathrm{C}, 1 \mathrm{~min} ; 72^{\circ} \mathrm{C}, 2.5 \mathrm{~min}$ were performed with a PTC- 100 thermocycler (MJ Research, Watertown, MA) followed by a final 10 -min, $72^{\circ} \mathrm{C}$ incubation.

\section{Cercosporin production assay.}

Mycelium suspensions were inoculated in PDB and incubated in the light for 4 days. Entire cultures (mycelium plus medium) were blended in a Waring blender for two 20-s pulses. A 10-ml aliquot of the suspension was treated with 1 vol of $5 \mathrm{~N} \mathrm{KOH}$ (Jenns et al. 1989) in darkness for $4 \mathrm{~h}$ and clarified by low speed centrifugation. The pelleted mycelium was lyophilized and used for dry weight determination. Cercosporin concentrations in the supernatants were determined spectrophotometrically (Yamazaki and Ogawa 1972). Three culture flasks were assayed for each strain in the experiment and the entire experiment was repeated.

\section{Cercosporin sensitivity assay.}

Mycelium plugs, $5 \mathrm{~mm}$ in diameter, were inoculated mycelium side down onto divided petri plates containing PDA with one half of each plate amended with cercosporin dissolved in acetone to a final concentration of $10 \mu \mathrm{M}$, and the other half amended with an equal volume of acetone (Daub 1987). Radial growth was measured in two perpendicular directions after 4 days of incubation in light or darkness. Growth inhibition was calculated from measurements of each strain on cercosporin medium as a percentage of its growth on medium lacking cercosporin. Four colonies of each strain were measured for the experiment and the experiment was repeated.

\section{Fungal pathogenicity on soybean.}

One half gram of washed, dark-grown mycelium of each strain tested was placed in $20 \mathrm{ml}$ of sterile water and blended in a Waring blender twice (two 20-s pulses). Mycelium suspensions were then sprayed, with a Preval atomizer (Yonkers, NY), onto the underside of leaves of 5-week-old soybean plants (cv. Lee-68). To promote infection, the plants were then placed in plastic bags and in reduced light for $48 \mathrm{~h}$ prior to being placed on benchtops in the greenhouse. Disease severity was assessed after 14 days (Upchurch et al. 1991). Six plants were inoculated with each fungal strain and the entire experiment was repeated.

\section{ACKNOWLEDGMENTS}

We thank T. Murakami (Meiji Seika Kaisha Ltd., Yokohama, Japan) for kindly providing bialaphos, O. C. Yoder (Cornell University, Ithaca, NY) for the gift of plasmids pBPIT and pUCHI, and R. P. Oliver (University of East Anglia, U.K.) for supplying plasmid pNOM102.

\section{LITERATURE CITED}

Alexander, N. J., Hohn, T. M., and McCormick, S. P. 1997. Molecular characterization of TRI12 which encodes an apparent transport protein involved in trichothecene production by Fusarium sporotrichioides. Cereal Res. Commun. 25:347-348.

Altschul, S. F., Gish, W., Miller, W., Myers, E. W., and Lipman, D. J. 1990. Basic local alignment search tool. J. Mol. Biol. 215:403-410.

Assante, G., Locci, R., Camarda, L., Merlini, L., and Nasini, G. 1977. Screening of the genus Cercospora for secondary metabolites. Phytochemistry 16:243-247.

Daub, M. E. 1982a. Cercosporin, a photosensitizing toxin from Cercospora species. Phytopathology 72:370-374.

Daub, M. E. 1982b. Peroxidation of tobacco membrane lipids by the photosensitizing toxin, cercosporin. Plant Physiol. 69:1361-1364.

Daub, M. E. 1987. The fungal photosensitizer cercosporin and its role in plant disease. ACS Symp. Ser. 339:271-280.

Daub, M. E., Ehrenshaft, M., Jenns, A. E., and Chung, K. R. 1998. Active oxygen in fungal pathogenesis of plants: The role of cercosporin in Cercospora diseases. Pages 31-56 in: Advances in Phytochemistry. J. Romero, K. Downum, and R. Verpoorte, eds. Plenum Press, New York.

Daub, M. E., and Hangarter, R. P. 1983. Light-induced production of singlet oxygen and superoxide by the fungal toxin, cercosporin. Plant Physiol. 73:855-857.

Daub, M. E., Leisman, G. B., Clark, R. A., and Bowden, E. F. 1992. Reductive detoxification as a mechanism of fungal resistance to singlet-oxygen-generating photosensitizers. Proc. Natl. Acad. Sci. USA 89:9588-9592.

Edelmann, S. E., and Staben, C. 1994. A statistical analysis of sequence features within genes from Neurospora crassa. Exp. Mycol. 18:7081.

Ehrenhofer-Murray, A. E., Wuergler, F. E., and Sengstag, C. 1994. The Saccharomyces cerevisiae SGE1 gene product: A novel drugresistance protein within the major facilitator superfamily. Mol. Gen. Genet. 224:287-294

Ehrenshaft, M., Chung, K. R., Jenns, A. E., and Daub M. E. 1999. Functional characterization of $S O R 1$, a gene required for resistance to photosensitizing toxins in the fungus Cercospora nicotianae. Curr. Genet. 34:478-485.

Ehrenshaft, M., Jenns, A. E., Chung, K. R., and Daub, M. E. 1998. SOR1, a gene requires for photosensitizer and singlet oxygen resistance in Cercospora fungi, is highly conserved in divergent organisms. Mol. Cell 1:603-609.

Ehrenshaft, M., and Upchurch, R. G. 1991. Isolation of light-enhanced cDNAs of Cercospora kikuchii. Appl. Environ. Microbiol. 57:26712676.

Garber, R. C., and Yoder, O. C. 1983. Isolation of DNA from filamentous fungi and separation into nuclear, mitochondrial, ribosomal, and plasmid components. Anal. Biochem. 135:416-422. 
Gish, W., and States, D. J. 1993. Identification of protein coding regions by database similarity search. Nat. Genet. 3:266-272.

Hightower R. C., Callahan, T. M., and Upchurch, R. G. 1995. Electrophoretic karyotype of Cercospora kikuchii. Curr. Genet. 27:290-292.

Hoffman, K., and Stoffel, W. 1993. Tmbase-A database of membrane spanning protein segments. Biol. Chem. Hoppe-Seyler. 347:166.

Jenns, A. E., and Daub, M. E. 1995. Characterization of mutants of Cercospora nicotianae sensitive to the toxin cercosporin. Phytopathology 85:906-912.

Jenns, A. E., Daub, M. E., and Upchurch, R. G. 1989. Regulation of cercosporin accumulation in culture by medium and temperature manipulation. Phytopathology 79:213-219.

Jenns, A. E., Scott. D. L., Bowden, E. F., and Daub, M. E. 1995. Isolation of mutants of the fungus Cercospora nicotianae altered in their response to singlet-oxygen-generating photosensitizers. Photochem. Photobiol. 61:488-493.

Kyte, J., and Doolittle, R. F. 1982. A simple method for displaying the hydrophobic character of a protein. J. Mol. Biol. 157:105-132.

Leisman, G. B., and Daub, M. E. 1992. Singlet oxygen yields, optical properties, and phototoxicity of reduced derivatives of the photosensitizer cercosporin. Photochem. Photobiol. 55:373-379.

Lousberg, R. L. J. C., Weiss, U., Salemink, C. A., Merlini, A., and Nasini, G. 1971. The structure of cercosporin, a naturally occurring quinone. J. Chem. Soc. Chem. Commun. 1971:1463-1464.

Lynch, F. J., and Geoghegan, M. J. 1979. Regulation of growth and cercosporin photoinduction in Cercospora beticola. Trans. Br. Mycol. Soc. 73:311-327.

Macri, F. A., and Vianello, M. 1979. Photodynamic activity of cercosporin on plant tissues. Plant Cell Environ. 2:267-271.

Marger, M. D., and Saier, M. H. 1993. A major superfamily of transmembrane facilitators that catalyze uniport, synport and antiport. Trends Biochem. Sci. 18:13-20.

Okubo, A., Yamazaki, S., and Fuwa, K. 1975. Biosynthesis of cercosporin. Agric. Biol. Chem. 39:1173-1175.

Paulsen, I. T., Brown, M. H., Littlejohn, T. G., Mitchell, B. A., and Skurray, R. A. 1996a. Molecular characterization of the multidrug resistance proteins QacA and QacB: Membrane topology and identification of residues involved in specificity for divalent cations. Proc. Natl. Acad. Sci. USA 93:3630-3635.

Paulsen, I. T., Brown, M. H., and Skurry, R. H. 1996b. Proton-dependent multidrug efflux systems. Microbiol. Rev. 60:575-608.
Pineiro, M., Garcia-Olmedo, F., and Diaz, I. 1994. Redox modulation of the expression of bacterial genes encoding cysteine-rich proteins in plant protoplasts. Proc. Natl. Acad. Sci. USA 91:3867-3871.

Pitkin, J. W., Panaccione, D. G., and Walton, J. D. 1996. A putative cyclic peptide efflux pump encoded by the TOXA gene of the plantpathogenic fungus Cochliobolus carbonum. Microbiology 142:1557565

Quigley, N. B., Mo, Y.-Y., and Gross, D. C. 1993. SyrD is required for syringomycin production by Pseudomonas syringae pathovar syringae and is related to a family of ATP-binding secretion proteins. Mol. Microbiol. 9:787-801.

Roberts, I. N., Oliver, R. P., Punt, P. J., and van den Hondel, C. A. M. J J. 1989. Expression of the Escherichia coli $\beta$-glucuronidase gene in industrial and phytopathogenic filamentous fungi. Curr. Genet. 15:177-180.

Rollins, J. A., Ehrenshaft, M., and Upchurch, R. G. 1993. Effects of light and altered-cercosporin phenotypes on gene expression in $\mathrm{Cer}$ cospora kikuchii. Can. J. Microbiol. 39:118-124.

Sambrook, J., Fritsch, E. F., and Maniatis, T. A. 1989. Molecular Cloning: A Laboratory Manual. 2nd ed. Cold Spring Harbor Laboratory, Cold Spring Harbor, NY.

Sollod-Cooperman, C., Jenns, A. E., and Daub, M. E. 1992. Cell surface redox potential as a mechanism of defense against photosensitizers in fungi. Appl. Environ. Microbiol. 58:444-449.

Straubinger, B., Straubinger, E., Wirsel, S., Turgeon, G., and Yoder, O. 1992. Versatile fungal transformation vectors carrying the selectable bar gene of Streptomyces hygroscopicus. Fungal Genet. Newsl. 39: 82-83.

Turgeon, B. G., Garber, R. C., and Yoder, O. C. 1987. Development of a fungal transformation system based on selection of sequences with promoter activity. Mol. Cell. Biol. 7:3297-3305

Upchurch, R. G., Meade, M. J., Hightower, R. C., Thomas, R. S., and Callahan, T. M. 1994. Transformation of the fungal soybean pathogen Cercospora kikuchii with the selectable marker bar. Appl. Environ. Microbiol. 60:4592-4595.

Upchurch, R. G., Walker, D. C., Rollins, J. A., Ehrenshaft, M., and Daub, M. E. 1991. Mutants of Cercospora kikuchii altered in cercosporin synthesis and pathogenicity. Appl. Environ. Microbiol. 57: 2940-2945.

Yamazaki, S., and Ogawa, T. 1972. The chemistry and stereochemistry of cercosporin. Agric. Biol. Chem. 36:1707-1718. 